\title{
EXPERIMENT AND STABILITY ANALYSIS ON HEAVY-DUTY SCAFFOLD SYSTEMS WITH TOP SHORES
}

\author{
Jui-Lin Peng ${ }^{1, *}$, Chung-Sheng Wang ${ }^{2}$, Chung-Wei $\mathrm{Wu}^{3}$ and Wai-Fah Chen ${ }^{4}$ \\ 1.Professor, Department of Civil and Construction Engineering, \\ National Yunlin University of Science and Technology, Taiwan, China \\ 2.Ph.D. Student, Graduate School of Engineering Science and Technology, \\ National Yunlin University of Science and Technology, Taiwan, China \\ 3.Ph.D., Graduate School of Engineering Science and Technology, \\ National Yunlin University of Science and Technology, Taiwan, China \\ ${ }^{4}$ Research Professor, Department of Civil Engineering, University of Hawaii, USA \\ *(Corresponding author: E-mail pengjl@yuntech.edu.tw)
}

Received: 8 February 2017; Revised: 27 March 2017; Accepted: 25 May 2017

\begin{abstract}
The heavy-duty scaffold system has a higher load capacity than the frame-type steel scaffold system. The independent setup of heavy-duty scaffold system is totally different from a row-style setup of frame-type steel scaffold system in construction. This study explores the load capacity and failure model of full-scale heavy-duty scaffold systems to elucidate their stability behaviors. The results of the study based on lab tests reveal that the load capacity and failure model of an independent three-story heavy-duty scaffold are similar to those of an independent two-story heavy-duty scaffold, with no apparent reduction in the load capacity. For a given height of the structure, the load capacity of a combination of independent two-story heavy-duty scaffolds with steel shores that are made of thin tubes is much lower than that of an independent three-story heavy-duty scaffold. In load tests on outdoor heavy-duty scaffolds with steel shores made of thin tubes, after loading, the entire structural system failed promptly without warning. A second-order inelastic analysis herein demonstrates that the tested and analyzed load capacities of various setups of heavy-duty scaffold systems are very close, revealing that the second-order inelastic analysis is suitable for heavy-duty scaffold systems. On construction sites in Taiwan, heavy-duty scaffolds with shores are often adopted, and the load capacity of the overall combined scaffold system is estimated from the strength of a single member used in the design of a traditional building steel structure. Hence, the load capacity of a heavy-duty scaffold system that is combined with shores of a thin tube tends to be overestimated, leading to a very high risk of collapse the combined scaffold system. Therefore, on a construction site, such a combined setup should be avoided. A heavy-duty scaffold system without any other shores on the top should be used on construction sites.
\end{abstract}

Keywords: Critical load, failure model, heavy-duty scaffold, load capacity, stability

DOI: $10.18057 /$ IJASC.2017.13.3.6

\section{INTRODUCTION}

The external configuration of heavy-duty scaffolds differs from that of frame-type steel scaffolds. Unlike frame-type steel scaffolds, which are typically set up continuously end-to-end in a single row, heavy-duty scaffolds are often set up independently. Features of heavy-duty scaffolds include their easy and quick setup, the lack of a difference between the strong axis and the weak axis in the scaffold system, and the independence setup from the environmental conditions. Owing to their large load capacity, heavy-duty scaffolds are typically used as falsework for heavy-laden slabs and beams during the construction of a building. They are often used in reinforced concrete structures, such as hi-tech fabrication plants, warehouses and bridges. The use of heavy-duty scaffolds in coordination with modular formwork systems is more convenient than the use of the frame-type steel scaffolds. Therefore, in the construction of heavy-laden reinforced concrete structures, heavy-duty scaffolds are gradually replacing frame-type steel scaffolds. 
Currently, no code for the structural design of heavy-duty scaffolds during construction is available in Taiwan. Heavy-duty scaffolds are commonly set up on a construction site based on the experience of construction workers. Since a construction contractor cannot effectively control the load capacity of heavy-duty scaffolds, the risk of collapse of such a scaffold system in service is very high. Figure 1 presents the falsework collapse that occurred during the construction of the access bridge for the 921 Earthquake Museum in Taichung, Taiwan.

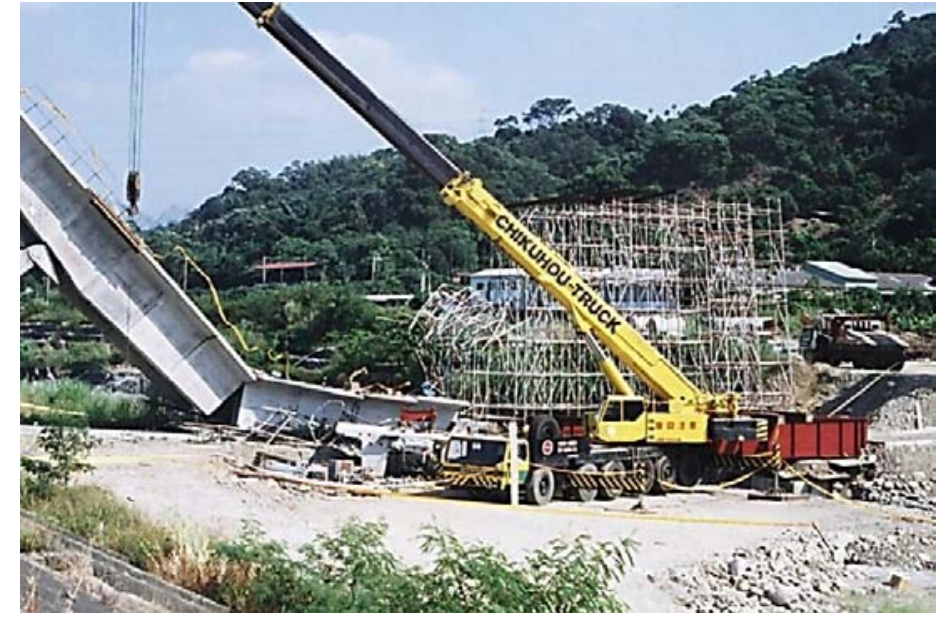

Figure 1. Collapse of Falsework in Construction of Access Bridge of 921 Earthquake Museum in Taichung, Taiwan

Numerous studies of the safety of steel scaffolds have been published. Huang et al. [4] developed a simplified 2-D model of door-type steel scaffolds, based on which they created a characteristic equation for the structural stability of door-type steel scaffolds with different numbers of stories. Peng et al. [9] explored the variation of axial forces of vertical steel tubes in an outdoor full-scale door-type steel scaffold system under different load paths of fresh concrete. Kuo et al. [6] and Peng et al. [11] investigated the axial forces of vertical steel tubes of door-type steel scaffold systems that are combined with wooden shores under different load paths and load types, and they examined the relationship between the influence-line effect and these loads. Whereas Kuo et al. conducted experiments on the rectangular arrangement of the outdoor full-scale steel scaffold system, Peng et al. analyzed rectangular, L-shaped and U-shaped arrangements of the door-type steel scaffold system.

Peng et al. [8] examined the load capacities of door-type steel scaffolds based on the single-row setup with many bays, which differed from that utilized in other tests, in which only one bay was involved. Previously Peng et al. [7] had performed load tests on isolated heavy-duty scaffolds to evaluate the load capacity and determine the failure model of such scaffolds with different arrangements.

With respect to single tube scaffolds, Liu et al. [5] carried out load tests on a full-scale large steel scaffolds without X-bracing to determine the load capacity and mechanical behaviors of the overall scaffold system. With respect to system scaffolds, Peng et al. [10] performed the second-order analyses and load tests on system scaffolds to determine the load capacity and mechanical behaviors of such scaffolds with different arrangements.

Zhang and Rasmussen (Zhang et al. [12]) explored the variability of parameters that affect the strength of steel scaffolds. They studied semi-rigid joint stiffness, load eccentricity, initial geometric imperfection, and system reliability. Zhang and Rasmussen (Zhang et al. [13]) 
subsequently explored the failure model of steel scaffolds, random variables that affect the strength of the scaffold structure, and the reliability of their analysis. Their results revealed that the reliability framework can improve the current working load limit of such a scaffold structure.

As indicated above, most relevant studies concern frame-type steel scaffolds, door-type steel scaffolds, single tube scaffolds and system scaffolds, whereas only a few have addressed heavy-duty scaffolds. Since heavy-duty scaffolds are set up as an independent tower structure, which differs from the aforementioned continuous scaffolding structures, the results of the majority of studies cannot be directly applied to the heavy-duty scaffolds, and especially not to the mechanical behaviors of the large area heavy-duty scaffold systems. Therefore, the load capacities and failure models of full-scale heavy-duty scaffold systems are worthy of further study.

\section{RESEARCH OBJECTIVES}

This study investigates the stability behavior of the heavy-duty scaffold system regarding the load capacity and the failure model of the system. All tested scaffolds are made of full-scale members and testing installations are based on the setups adopted on real construction sites. The results of this study may provide a reference for the safe design and construction of heavy-duty scaffolds in the construction industry in Taiwan to reduce the risk of collapse. This study makes the following contributions.

- Load tests are performed on the independent heavy-duty scaffolds and the heavy-duty scaffolds that are combined with shores, to determine the load capacities and failure models of various setups of these heavy-duty scaffolds.

- Second-order inelastic analyses of independent heavy-duty scaffolds is performed, and the analytical results are compared with the test results to evaluate the analytical parameters of scaffolds, such as the joint stiffness of each member.

- Load tests on an outdoor full-scale heavy-duty scaffold system that is combined with shores are performed to evaluate the actual load capacity and failure model of such a system.

- The applicability of second-order inelastic analysis is determined by comparing indoor and outdoor test results with the results of the second-order inelastic analysis.

The Geometric and Material Nonlinear Analysis of Frames (GMNAF) that were developed by professor Siu-Lai Chan of The Hong Kong Polytechnic University (Chan [1], Chan et al. [2, 3]) are used in the 3D second-order inelastic analysis herein with semi-rigid joints for various setups of heavy-duty scaffold systems.

\section{DIMENSIONS AND MATERIAL PROPERTIES}

The heavy-duty scaffolds that are most commonly used on construction sites in Taiwan were adopted in this study. The A heavy-duty scaffolding structure is composed of a triangle-type scaffold unit, lateral braces and horizontal bars. The triangle-type scaffold unit is composed of the main rod, upper rods, middle rods and diagonal braces (as shown in Figure 2).

The cross-sectional dimensions of various members are obtained from measurements of six sets of heavy-duty scaffolds. In Figure 2, the measurements of the cross-sections of various members of the triangle-type scaffold unit were as follows; the average external diameter and thickness of the main rod were $76.35 \mathrm{~mm}$ and $3.32 \mathrm{~mm}$, respectively (see cross section A-A); the average external diameter and thickness of the upper rod were $42.26 \mathrm{~mm}$ and $2.24 \mathrm{~mm}$, respectively (see cross section B-B); the average external diameter and thickness of the middle rod were $33.62 \mathrm{~mm}$ and 
$2.24 \mathrm{~mm}$, respectively (see cross section $\mathrm{C}-\mathrm{C}$ ); the average external diameter and thickness of the diagonal brace were $33.63 \mathrm{~mm}$ and $2.18 \mathrm{~mm}$ respectively (see cross section $\mathrm{D}-\mathrm{D}$ ).
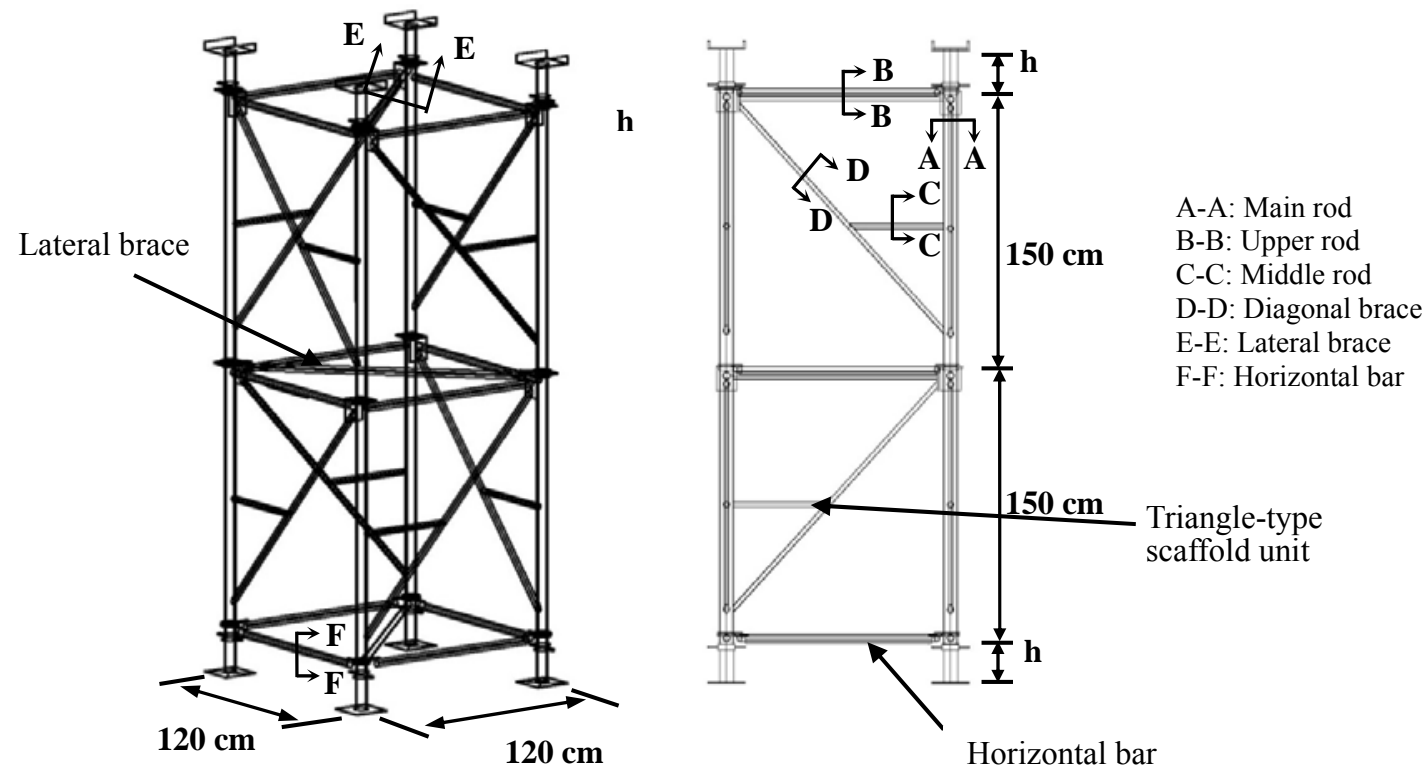

Figure 2. Dimensions and Setup of Internal Members of the Independent Heavy-duty Scaffolds

The measurements of lateral braces and horizontal bars were as follows; the average external diameter and thickness of the lateral braces were $42.27 \mathrm{~mm}$ and $1.92 \mathrm{mmm}$ respectively (see cross section E-E); the average external diameter and thickness of the horizontal bar were $42.35 \mathrm{~mm}$ and $2.40 \mathrm{~mm}$, respectively (see cross section F-F).

In the material tests, since all members of heavy-duty scaffolds are made of the same material, the coupon tests were performed on six randomly selected main rods of the heavy-duty scaffolds to determine the elastic modulus, $E$, of the heavy-duty scaffolds. The average elastic modulus, $E$, of the 6 main rods was $20,386 \mathrm{kN} / \mathrm{cm}^{2}$, which is very close to the nominal $E$ value $20,012.4 \mathrm{kN} / \mathrm{cm}^{2}$. Therefore, when the double modulus theory is used to conduct the second-order inelastic analysis of heavy-duty scaffolds, the reduced modulus, $E_{r}$, equals the elastic modulus, $E$, multiplied by a reduction factor, $\phi$. (i.e., $E_{r}=\phi E$ ).

\section{TEST PLAN}

In this study, two groups of tests were carried out: indoor and outdoor load tests. The indoor tests were carried out on both independent heavy-duty scaffolds and heavy-duty scaffolds that were combined with shores, to elucidate the effect of these two setups on load capacities and failure models. The outdoor test of heavy-duty scaffolds that were combined with shores simulated the heavy-duty scaffolding systems that are used on actual construction sites. All scaffolds used in these tests were the full-scale heavy-duty scaffolds.

\subsection{Indoor Load Tests on Independent Heavy-duty Scaffolds}

\subsubsection{Heavy-duty scaffolds}

Heavy-duty scaffolds with different numbers of stories have different load capacities. In this study, load tests were conducted on two-story and three-story independent heavy-duty scaffolds to explore 
the relation between load capacity of heavy-duty scaffolds and the number of stories. In the setup for testing heavy-duty scaffolds, lateral braces were used for each story; the height of each story was $150 \mathrm{~cm}$; the height of the top jack and the bottom jack bases was $20 \mathrm{~cm}$, and the total heights of the two-story and three-story systems were $340 \mathrm{~cm}$ and $490 \mathrm{~cm}$, respectively. Figure 3 displays the relevant arrangements.

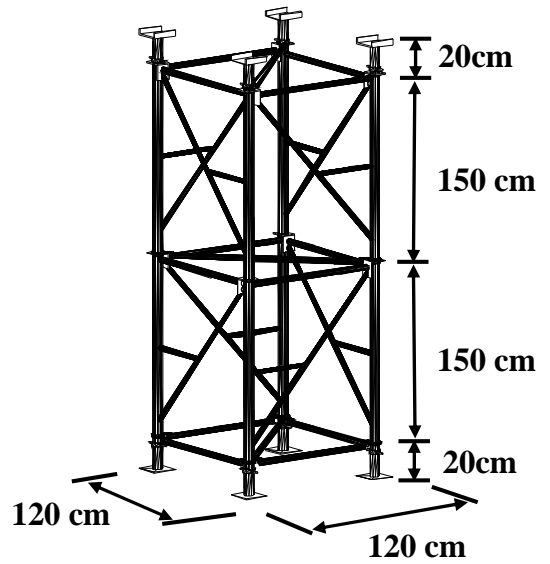

(A) 2-story

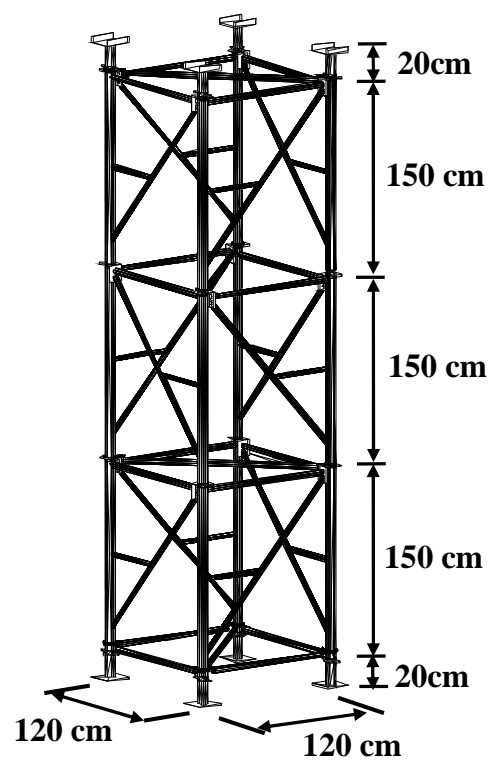

(B) 3-story

Figure 3. Dimensions and Configurations of Two-story and Three-story Heavy-duty Scaffolds

\subsubsection{Heavy-duty scaffolds with shores}

The headroom of a building will never be an exact integer multiple of the height of a heavy-duty scaffold. Therefore, when multiple stories of heavy-duty scaffolds are set up, a gap must exist between the top story and the bottom of the slab. To solve this practical problem, workers will often fill the gap with shores, such as steel shores, wooden shores or tubular steel adjustable shores. The difference between the load capacity of heavy-duty scaffolds without and with shores is worth of study.

In the tests on the heavy-duty scaffolds with shores, the steel tubes with different thicknesses and lengths were used on the top of the scaffolds. Figure 4 shows the test configuration. The "thick" steel shores are directly cut from the main rods of heavy-duty scaffolds, with an average external diameter of $76.35 \mathrm{~mm}$ and thickness of $3.32 \mathrm{~mm}$. Such thick steel shores are seldom adopted on construction sites, and they are used in this study simply for the purpose of comparison. The "thin" steel shores are made of galvanized steel tubes that are commonly used on construction sites in Taiwan, with an average external diameter of $48.18 \mathrm{~mm}$ and thickness of $2.00 \mathrm{~mm}$. On construction sites, the construction contractor uses thin steel shores mainly for convenience and cheapness. The tests herein reveal the upper and lower limits of the load capacity of heavy-duty scaffolds combined with shores.

\subsection{Outdoor Load Test on Heavy-duty Scaffolds with Shores}

\subsubsection{Resistance}

In this study, an outdoor load test on heavy-duty scaffolds with shores were conducted to explore the load capacity of actual heavy-duty scaffolds which is the lower limit strength of the system. Figures $5 \mathrm{~A}$ and $5 \mathrm{~B}$ show the setup of a heavy-duty scaffold system with shores in the outdoor load 
test. The bottom part of the system was composed of four sets of four-story heavy-duty scaffolds with a total height of $6 \mathrm{~m}$. On top of the heavy-duty scaffolds, 16 thin steel shores, each with a length of $1.5 \mathrm{~m}$ were set. Each group of four thin steel shores was reinforced with four horizontal braces.

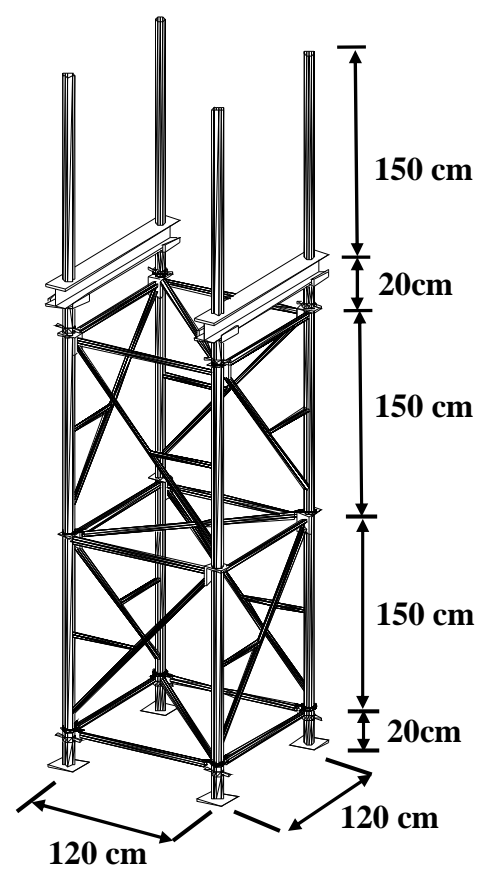

Figure 4. Dimensions and Configuration of Two-story Heavy-duty Scaffolds with 150cm-long Steel Shores on Top

In the outdoor load test, the heavy-duty scaffold system with shores was setup on a $5.4 \mathrm{~m} \times 5.4 \mathrm{~m}$ square area. As shown in Figures 5A and 5B, a set of heavy-duty scaffold was installed at each corner of this square. The top view area of each set of heavy-duty scaffolds was $1.2 \mathrm{~m} \times 1.2 \mathrm{~m}$ and the net distance between each set of heavy-duty scaffold was $3 \mathrm{~m}$. A theodolite was arranged on both the north and the west sides of the square area. During the tests, the horizontal displacements and directions of the H-beams between heavy-duty scaffolds and the thin steel shores were measured using the theodolite, as shown in Figures 5A and 5B.

As also shown in Figures 5A and 5B, the eight steel wire ropes above the thin steel shores on the upper-story provided the system with lateral support, to simulate the formwork of beams and slabs, supported by the dried reinforced concrete (RC) columns and walls. Thus, this scaffold framework should not exhibit any lateral displacement. The eight steel wire ropes on top of the heavy-duty scaffolds on the lower stores were used for safety as they stabilized the overall system during installation, reducing the risk of collapse. On the day of the tests, these eight steel wire ropes were detached before loading because such lateral bracing reinforcement is not used on a real construction site.

To prevent uneven settlement due to the heavy load on the base, four large RC blocks were firstly buried in the test field. Four H-beams were then laid on the RC blocks and the heavy-duty scaffolds were then set on these H-beams to spread uniformly the vertical load that was conveyed from the top of the heavy-duty scaffolds. 


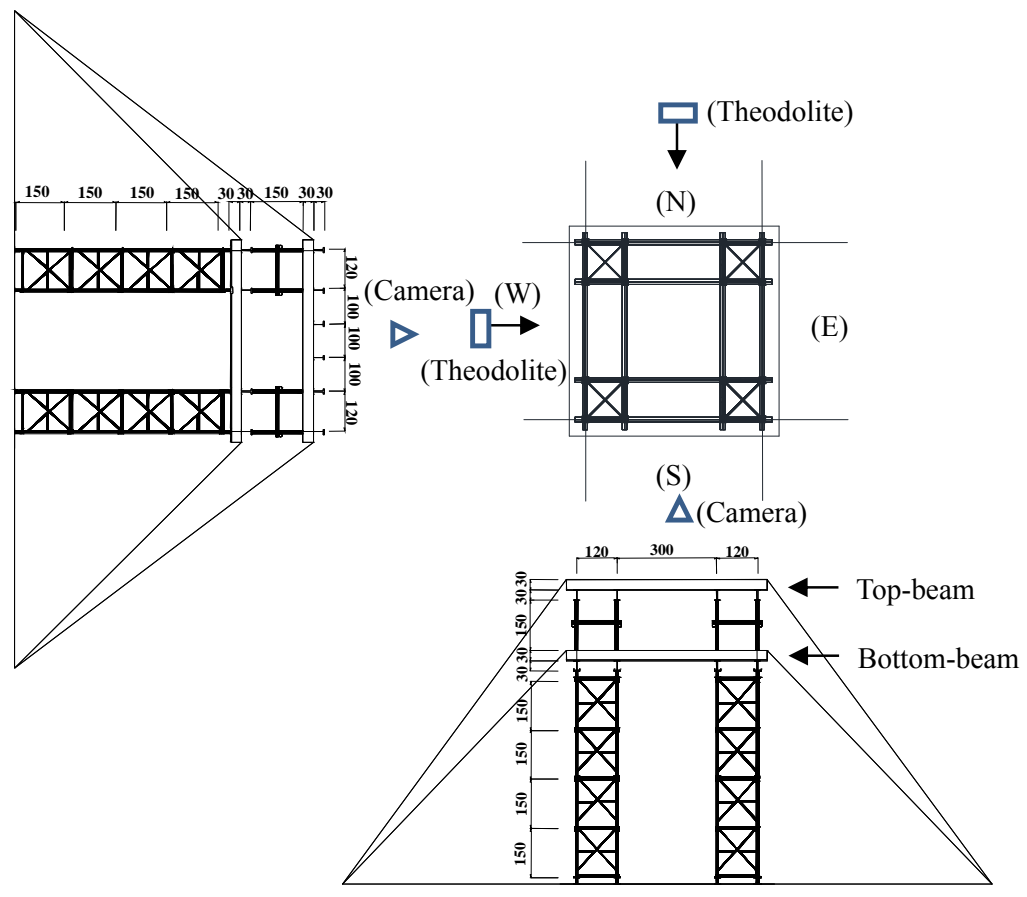

Figure 5A. Three-view Diagram of Setup for Outdoor Load Test of Heavy-duty Scaffolds with Shores

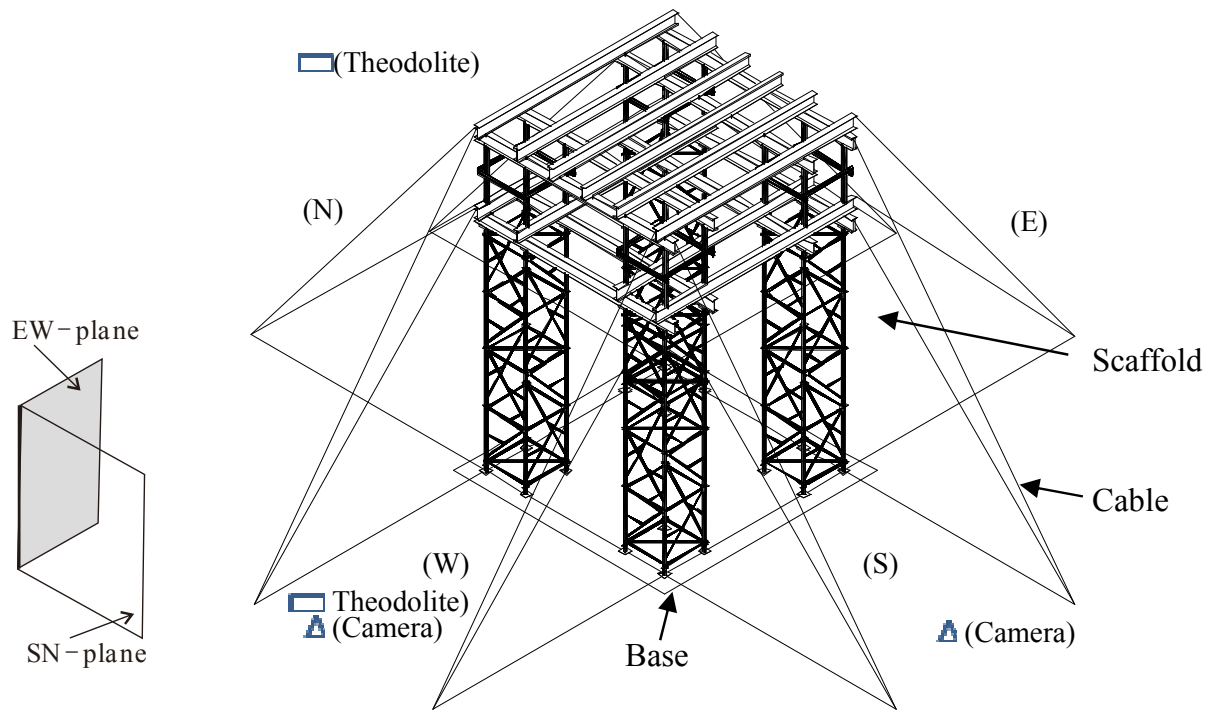

Figure 5B. Setup for Outdoor Load Test of Heavy-duty Scaffolds with Shores

\subsubsection{Load}

In the tests, $\mathrm{RC}$ blocks and sandbags simulated the load of fresh concrete during construction. The RC blocks were placed on two stories. Ten RC blocks were placed on each story, as shown in Figure 6. The same load procedure was used for both stories. For each story, only the first two RC blocks were placed adjacent to each other and the remaining eight RC blocks were placed diagonally. The placement mainly considered the evenness of the load distribution on the overall scaffold system. 
Figure 7 displays the order and positions of the placement of the sandbags: the numbers indicate the order of placement. Like the RC blocks, the sandbags were placed diagonally in an order that ensured the evenness of the load distribution on the overall scaffold system.

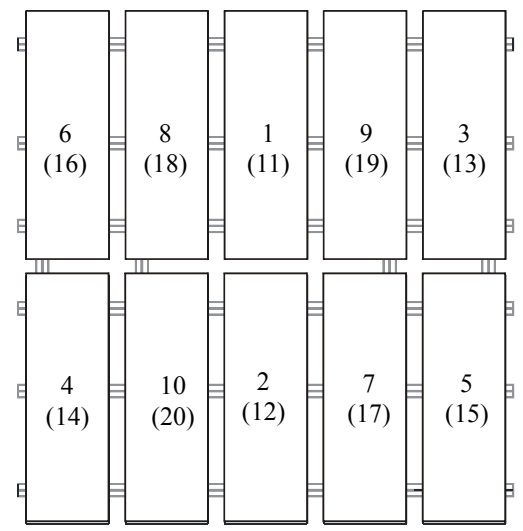

Figure 6. Placement of Two Stories of RC Blocks in Outdoor Load Test on Heavy-duty Scaffolds with Shores

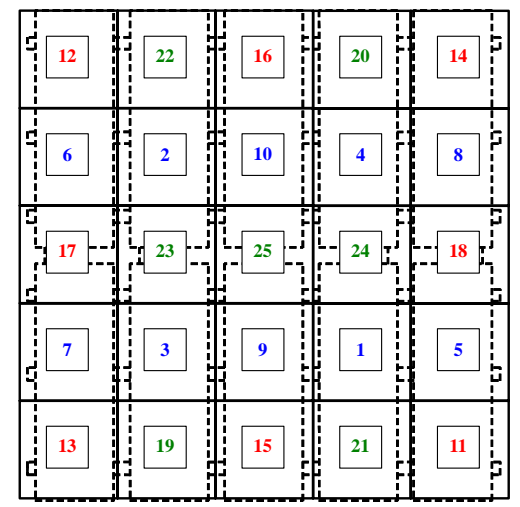

Figure 7. Placement of Sandbags on First Story in Outdoor Load Test on Heavy-duty Scaffolds with Shores

\section{TEST RESULTS AND ANALYSES}

\subsection{Indoor Load Tests on Independent Heavy-duty Scaffolds}

\subsubsection{Load capacity of heavy-duty scaffolds}

Three sets of load tests were conducted on the two-story heavy-duty scaffolds, yielding an average load capacity of $981.72 \mathrm{kN}$, as shown in Table 1 . The test result on the heavy-duty scaffold system can serve as a basis for comparison with the load capacities of other setups of heavy-duty scaffolds. Figure 8(A) shows the deformations of the two-story heavy-duty scaffolds under loading. Figure 9 plots the load-vertical displacement curve.

Two sets of load tests were conducted on the three-story heavy-duty scaffolds, and yielded an average load capacity of $921.31 \mathrm{kN}$, as shown in Table 1. Figure 8(B) shows the deformation of the three-story heavy-duty scaffolds under loading. Figure 10 plots the load-vertical displacement 
curve. Comparing the test results of the three-story heavy-duty scaffolds with those of the two-story heavy-duty scaffolds reveals that the average load capacity of the three-story heavy-duty scaffolds is about $93.8 \%(=(921.3 / 981.72) \times 100 \%)$ of that of the two-story heavy-duty scaffolds, so the difference between these two capacities is insignificant.

Table 1. Results of Indoor Load Tests on Independent Heavy-duty Scaffolds

\begin{tabular}{|c|c|c|c|c|c|c|c|}
\hline \multirow{2}{*}{ Setup type } & \multirow{2}{*}{$\begin{array}{c}\text { No. of } \\
\text { story }\end{array}$} & \multirow{2}{*}{ Figure } & \multirow{2}{*}{ Numbering } & \multicolumn{4}{|c|}{ Test values $(\mathrm{kN})$} \\
\hline & & & & Test A & Test B & Test C & Average \\
\hline \multirow[b]{2}{*}{ Setups of various heights } & 2 & & BUS2 & 990.88 & 1012.99 & 941.3 & 981.72 \\
\hline & 3 & 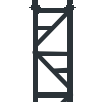 & BUS3 & 951.57 & 891.04 & \# & 921.31 \\
\hline $\begin{array}{c}150 \mathrm{~cm} \text {-long thick steel } \\
\text { shores on top }\end{array}$ & 2 & $\forall$ & TBUS2 & 773.18 & 817.1 & $\#$ & 795.14 \\
\hline $\begin{array}{l}150 \mathrm{~cm} \text {-long thin steel } \\
\text { shores on top }\end{array}$ & 2 & $\forall$ & TTBUS2 & 214.86 & 218.04 & $\#$ & 216.45 \\
\hline $\begin{array}{l}80 \mathrm{~cm} \text {-long thin steel } \\
\text { shores on top }\end{array}$ & 2 & $\forall$ & TTBUS2 & 327.59 & 330.0 & \# & 328.8 \\
\hline
\end{tabular}

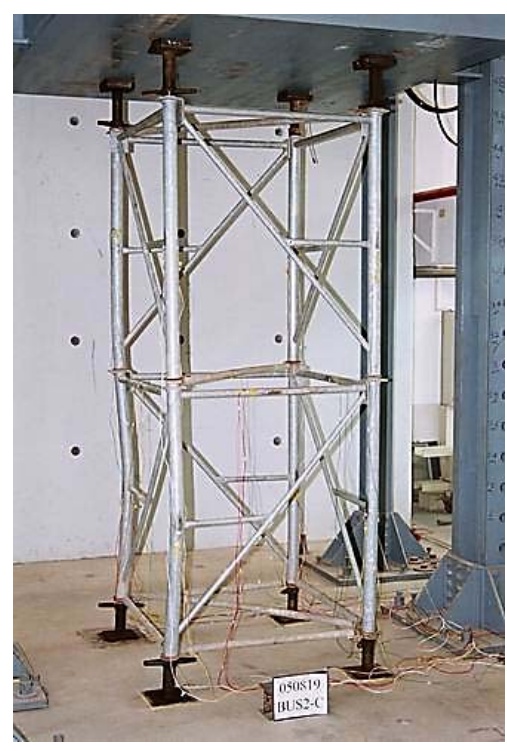

(A) 2-story

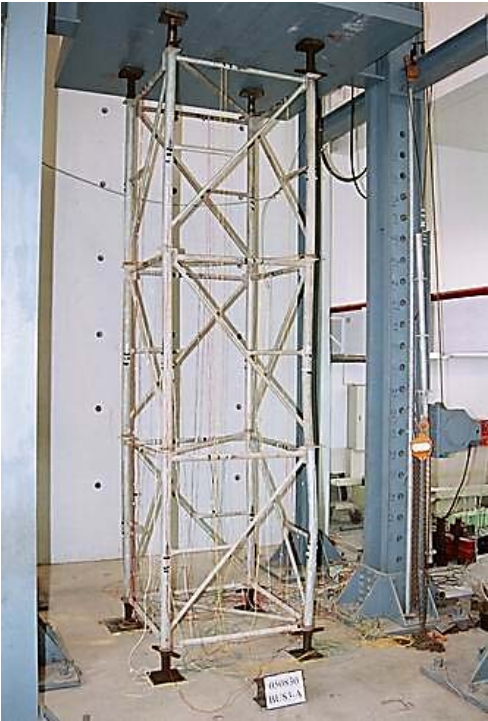

(B) 3-story

Figure 8. Deformations of Two-story and Three-story Heavy-duty Scaffolds under Loading 


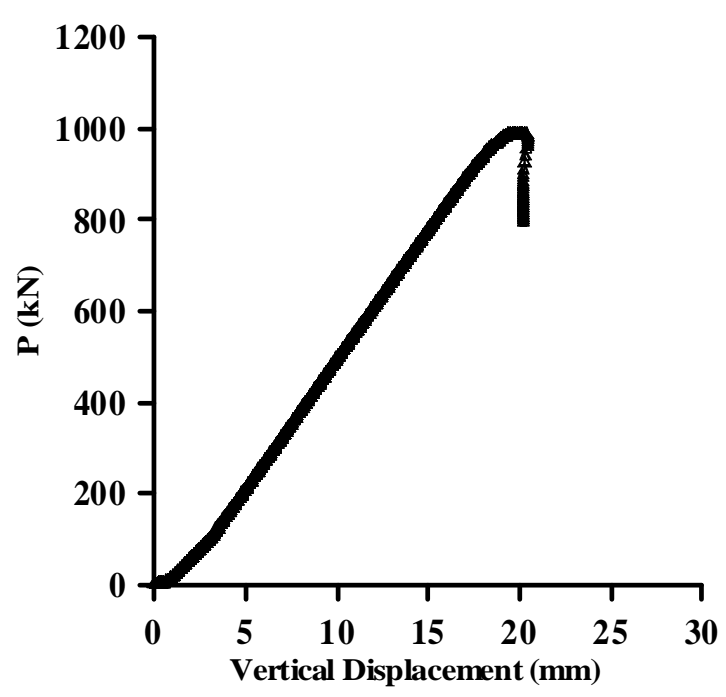

Figure 9. Load-vertical Displacement Curve from Load Test on Two-story Heavy-duty Scaffolds

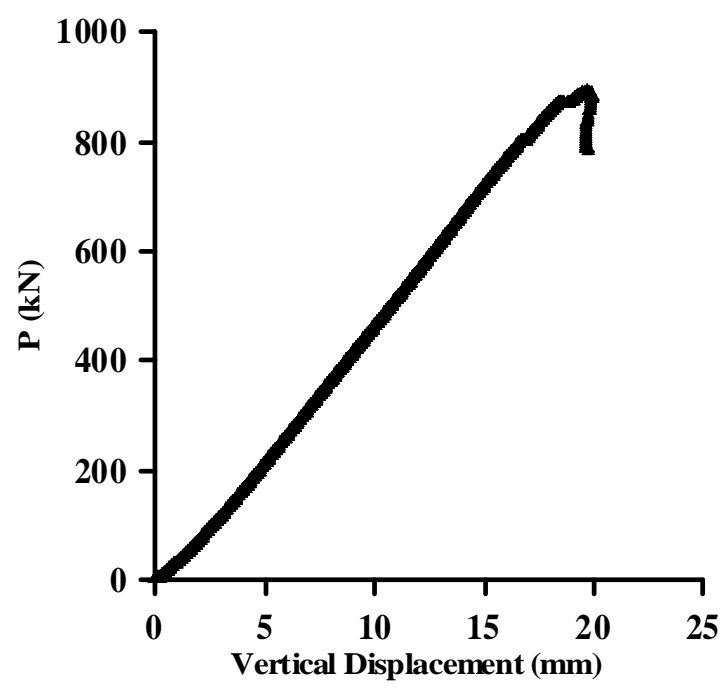

Figure 10. Load-vertical Displacement Curve from Load Test on Three-story Heavy-duty Scaffolds

\subsubsection{Load capacity of heavy-duty scaffolds with shores}

\subsubsection{150cm-Long thick steel shores on top of scaffold}

Two sets of load tests were performed on two-story heavy-duty scaffolds that were augmented with $150 \mathrm{~cm}-$ long and thick steel shores on the top of scaffolds. The average load capacity was 795.14 $\mathrm{kN}$, as shown in Table 1. Figure 11(A) shows the deformation of this heavy-duty scaffolds with the shores under loading. As shown in the figure, the $150 \mathrm{~cm}-$ long thick steel shores exhibits no significant deformation. Instead, nearly all of the deformation is in the heavy-duty scaffolds. Figure 12 plots the load-vertical displacement curve, which is similar to those of the two-story and three-story heavy-duty scaffolds. The load capacity of the heavy-duty scaffolds with shores is $86.3 \%(=(795.14 / 921.31) \times 100 \%)$ of that of the three-story heavy-duty scaffolds of the same height. 


\subsubsection{2 $150 \mathrm{~cm}$-long thin steel shores on top of scaffold}

Two sets of load tests were conducted on the two-story heavy-duty scaffolds that were augmented with $150 \mathrm{~cm}$-long and thin steel shores on the top of scaffolds. The average load capacity was $216.45 \mathrm{kN}$, as shown in Table 1. Figure 11(B) presents the deformation of this heavy-duty scaffolds with shores under loading. As shown in the figure, most of the deformation was in the thin steel shores, as the heavy-duty scaffolds exhibited no significant deformation. Figure 13 plots the load-vertical displacement curve, which differs from that of the two-story and three -story heavy-duty scaffolds, and reveals that the stiffness of the heavy-duty scaffolds with shores is less than either.

The load capacity of the heavy-duty scaffolds with shores $(216.45 \mathrm{kN})$ is $23.5 \%$ $(=(216.45 / 921.31) \times 100 \%)$ of that of the three-story heavy-duty scaffolds with the same height $(921.31 \mathrm{kN})$ and $27.2 \%(=(216.45 / 795.14) \times 100 \%)$ of that of the two-story heavy-duty scaffolds that were augmented with the $150 \mathrm{~cm}$-long thick steel shores on the top $(795.14 \mathrm{kN})$.

\subsubsection{80cm-long thin steel shores on top of scaffold}

Two sets of load tests were conducted on the two-story heavy-duty scaffolds that were augmented with $80 \mathrm{~cm}$-long thin steel shores on the top of scaffolds. The average load capacity was $328.8 \mathrm{kN}$, as shown in Table 1. Figure 11(C) plots the deformation of the heavy-duty scaffolds with shores under loading. As shown in the figure, most of the deformation occurs in the thin steel shores as the deformation of the heavy-duty scaffolds is insignificant. Figure 14 plots the load-vertical displacement curve, which is similar of the two-story heavy-duty scaffolds that were augmented with $150 \mathrm{~cm}$-long thin steel shores on the top of scaffolds.

The above test results demonstrate that the load capacity of the heavy-duty scaffolds with shores declines as the length of the augmented thin shores on top of the heavy-duty scaffolds increases. The load capacity of the heavy-duty scaffolds with thin steel shores on top is significantly smaller than that of the same heavy-duty scaffolds with thick steel shores on top. Nevertheless, in Taiwan, heavy-duty scaffolds with thin steel shores on top are commonly used on construction sites.

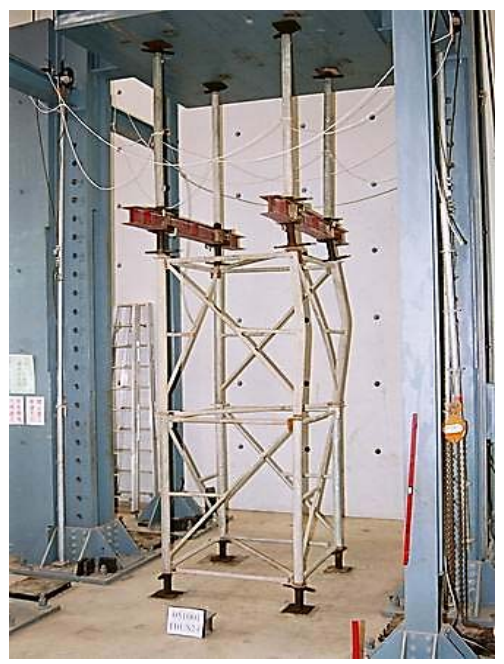

(A) $150 \mathrm{~cm}$-long thick steel shores

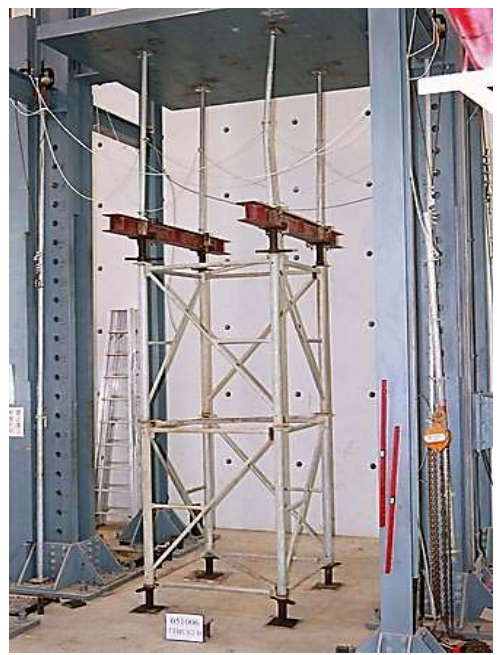

(B) $150 \mathrm{~cm}$-long thin steel shores

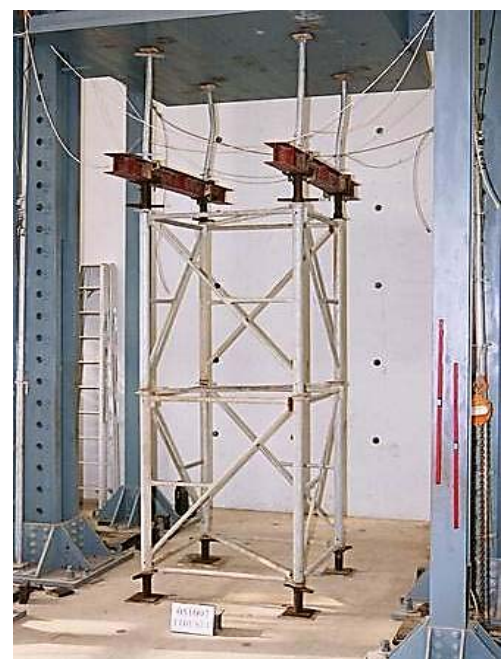

(C) $80 \mathrm{~cm}$-long thin steel shores

Figure 11. Deformations of Two-story Heavy-duty Scaffolds with Various Shores on Top under Loading 


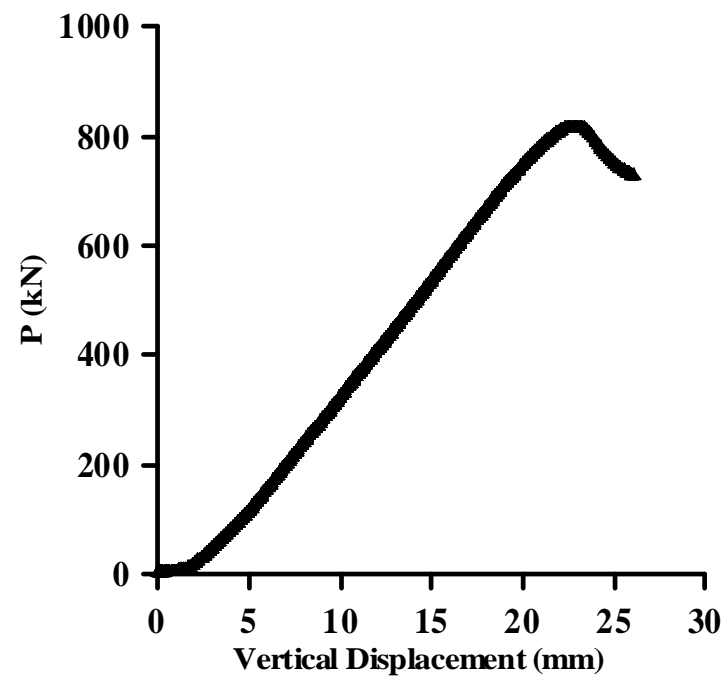

Figure 12. Load-vertical Displacement Curve from Load Test on Two-story Heavy-duty Scaffolds Augmented on Top with 150cm-long Thick Steel Shores

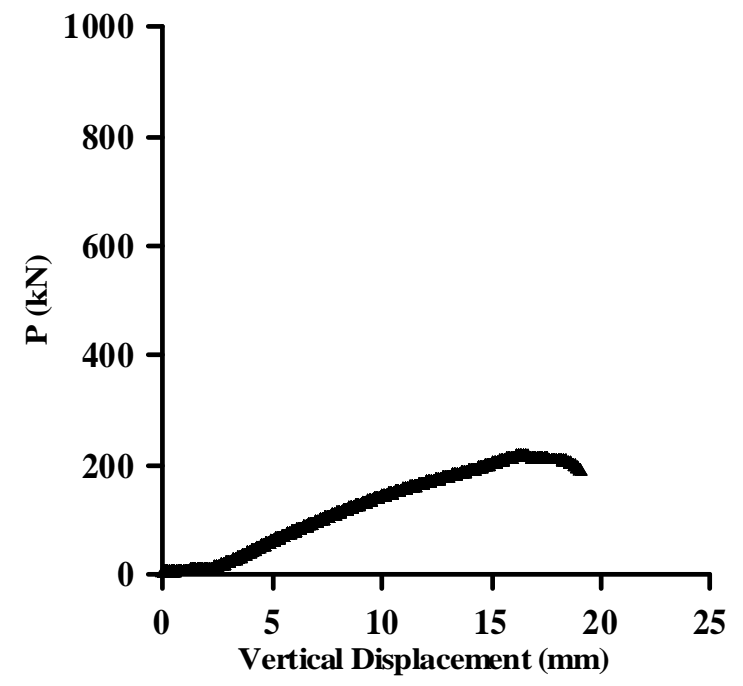

Figure 13. Load-vertical Displacement Curve from Load Test on Two-story Heavy-duty Scaffolds Augmented on Top with 150cm-long Thin Steel Shores 


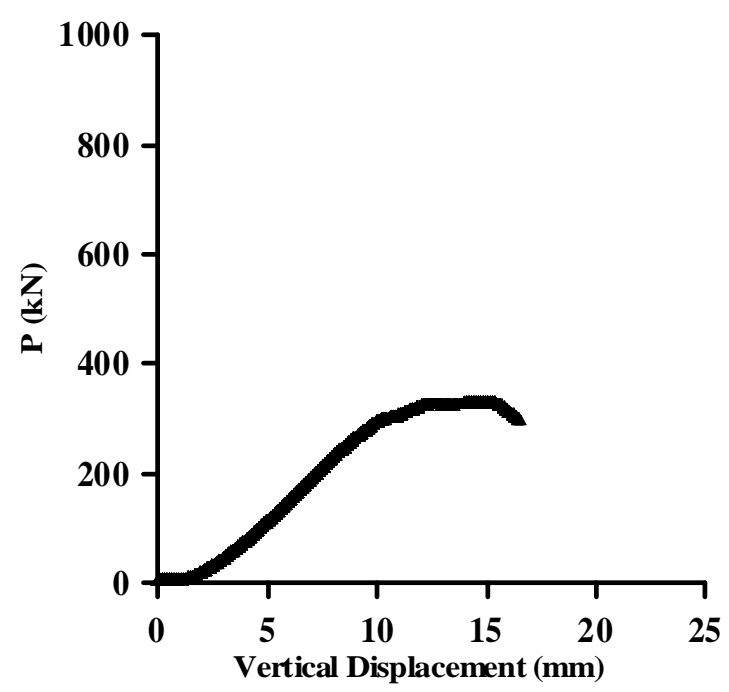

Figure 14. Load-vertical Displacement Curve from Load Test on

Two-story Heavy-duty Scaffolds Augmented on Top with 80cm-long Thin Steel Shores

\subsection{Outdoor Load Test on Heavy-duty Scaffold System with Shores}

\subsubsection{Load}

An outdoor full-scale heavy-duty scaffolds with $150 \mathrm{~cm}$-long thin steel shores on top were tested because this kind of combined setup is the most commonly used on construction sites in Taiwan. After two stories of RC blocks were laid down on the heavy-duty scaffolds in the specified order, the placement of sandbags began. After the first sandbag (No. 21 load block) was laid down on the system, the theodolite registered a slight but apparent eastward displacement of the top-story H-beams, similar to those observed in tests on indoor independent heavy-duty scaffolds with shores before failure. Figure 15 shows the load conditions of this heavy-duty scaffold system with shores before failure.

\subsubsection{Resistance}

\subsubsection{System failure}

In this test, the scaffold system failed entirely, instead of by a domino effect that was induced by the failure of a single member. When the first sandbag (No. 21 load block) was laid down, the overall system was determined to be liable to failure at any time, so field workers were dispersed rapidly and asked to wait for around 15 minutes while the system was observed. Before the second sandbag (No. 22 load block) was laid down, the overall heavy-duty scaffold system with shores collapsed suddenly without any warning.

During failure, the upper-story RC blocks and sandbags moved eastward, while the H-beams above the heavy-duty scaffolds moved westward under the pushing and jostling of the thin steel shores on the top story. The failure load of the heavy-duty scaffolds with shores was $363.405 \mathrm{kN}$.

In the tests, cameras were set up to the south and west of the heavy-duty scaffold system with shores to record the collapse process, as shown in Figs. 5A and 5B. Figures 16A and 16B present the collapse process as recorded from the south and west, respectively. As displayed in Figure 16A, the failure of the overall system is dominated by the deformation on the EW-plane (Figure 5B). As displayed in Figure 16B, hardly any lateral deformation on the SN-plane occurred (Figure 5B). 
As shown in Figures 16A and 16B, just before the collapse of the scaffold system, all members of the heavy-duty scaffolds and the above thin steel shores were intact, so the collapse of the heavy-duty scaffold system with shores was dominated by the buckling of the overall scaffold system, rather than by a domino effect that originated in the failure of a single member.

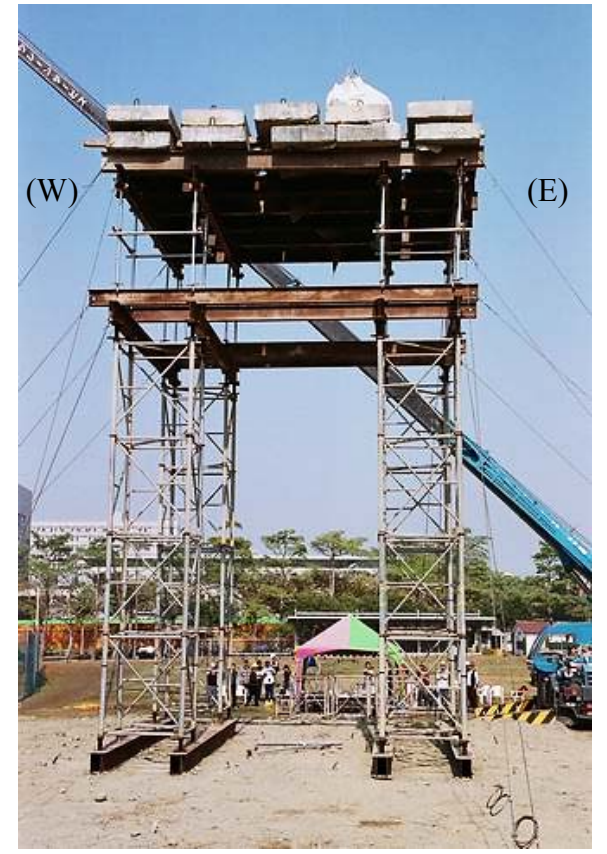

Figure 15. Load Application in Outdoor Test on Heavy-duty Scaffolds with Shores just before Collapse

\subsubsection{Description of system failure}

Table 2 presents the test results, which are converted into the load-displacement curves (P- $\Delta$ curves) in Figures 17 and 18. Figures 17 and 18 plot the lateral displacements of the upper- and lower-story H-beams, as observed by the theodolites that were set up to the north and the west of the scaffold system, respectively, when the system was loaded.

When the $20^{\text {th }}$ record was obtained, the total displacement of the upper-story H-beams was $15 \mathrm{~mm}$. When the $21^{\text {st }}$ record was obtained, the applied load was $363.405 \mathrm{kN}$, and the lateral displacement had increased abruptly to $10 \mathrm{~mm}$, for a total displacement of $25 \mathrm{~mm}$, which is clearly larger than that observed in tests on the indoor independent setup of scaffolds (as shown in Figures 13 and 14). At the $21^{\text {st }}$ recording moment, the outdoor scaffold system under loading was judged to have reached the critical load of system instability. Therefore, the test loading stopped for around 15 minutes to enable the system to be quietly observed. Before the $22^{\text {nd }}$ sandbag was laid down, the overall heavy-duty scaffold system with shores collapsed suddenly without any warning.

Obviously, this structural system was under only vertical loads - and no lateral loads. Under a fixed vertical load in a static state, the overall structural system collapsed without the failure of any single member. This failure model should be regarded as a typical system buckling that is caused by the structural system instability. When loading reaches the critical load of the structural system, the overall system buckles and collapses by a minor disturbance owing to its unstable equilibrium. Figure 19 schematically depicts the overall buckling and collapse of a heavy-duty scaffold system with shores owing to instability. 


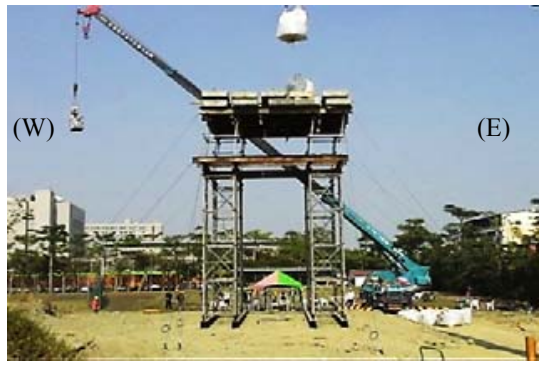

(1)

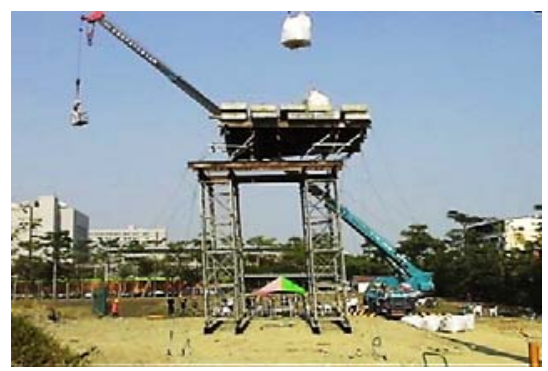

(2)

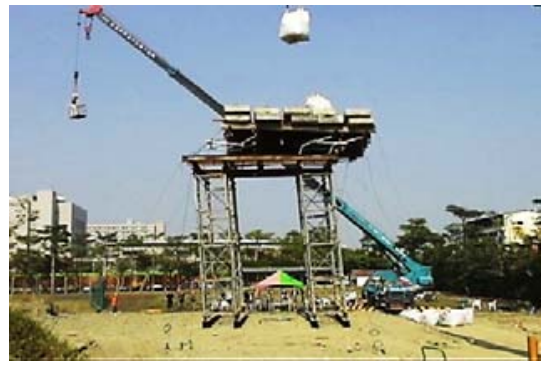

(3)

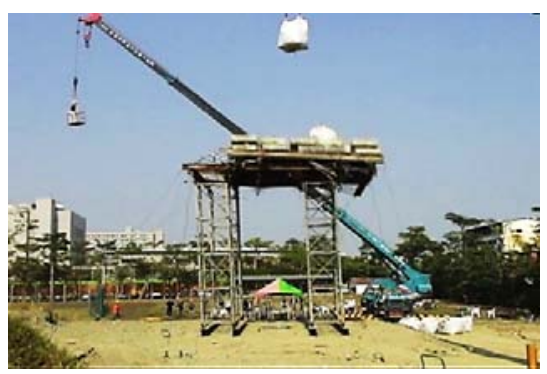

(4)

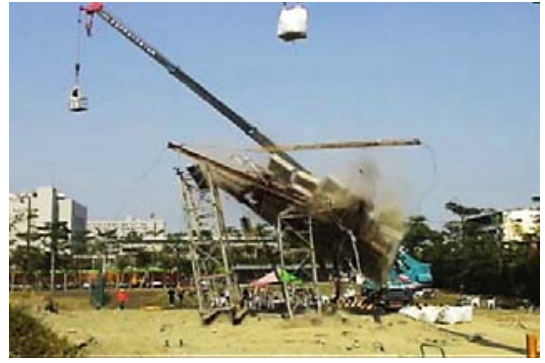

(5)

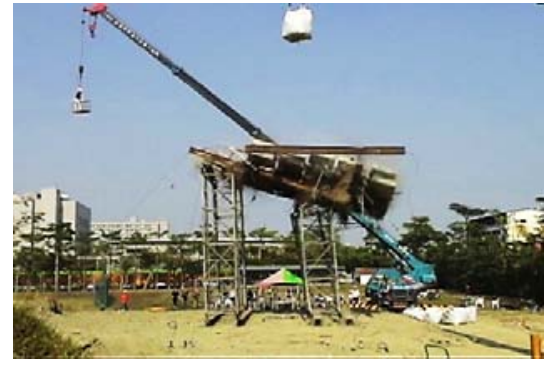

(6)

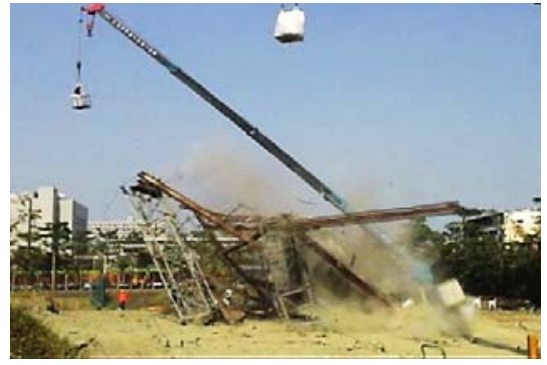

(7)

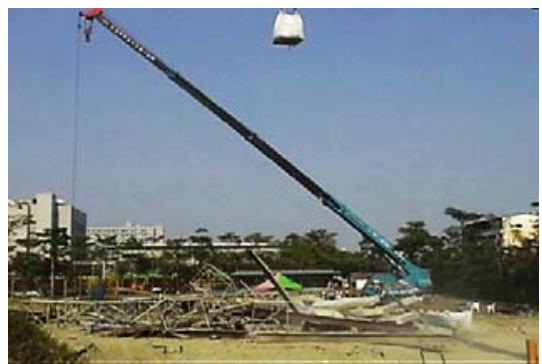

(8)

Figure 16A. Collapse of Outdoor Heavy-duty Scaffolds with Shores under Loading, as Recorded by Camera on the South 


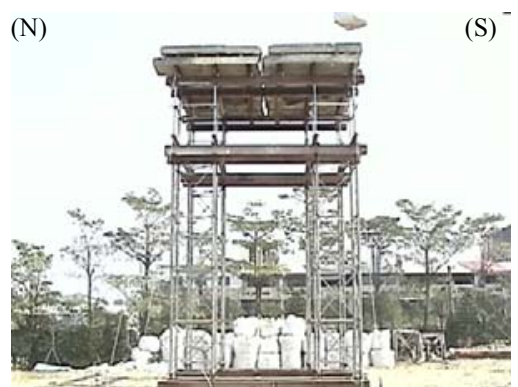

(1)

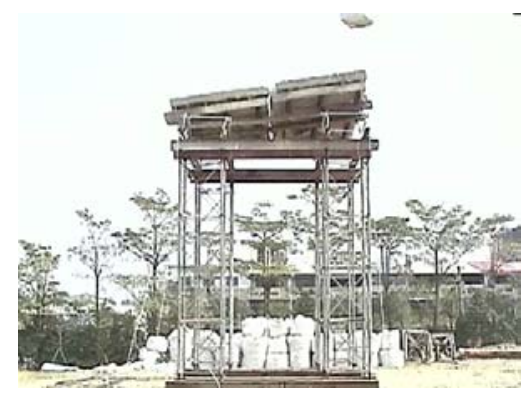

(2)

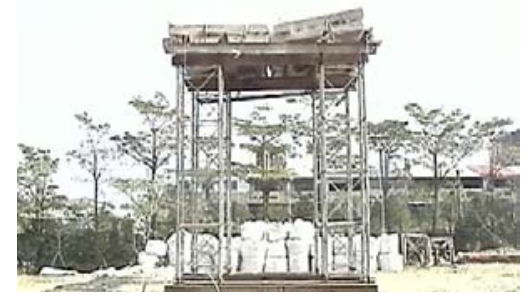

(3)

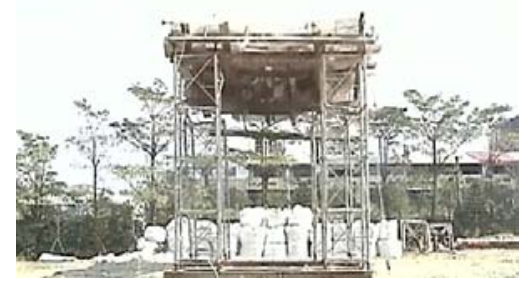

(4)

$(\mathrm{S})^{-}$

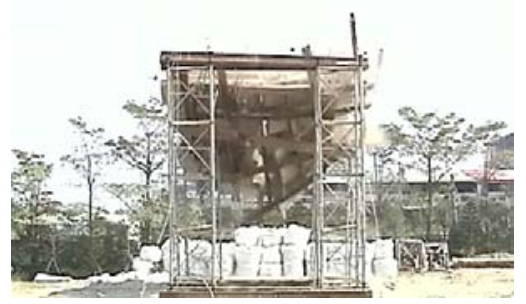

(5)

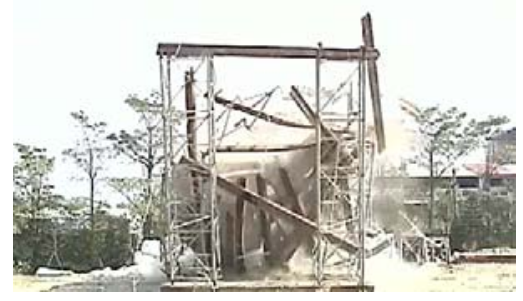

(6)

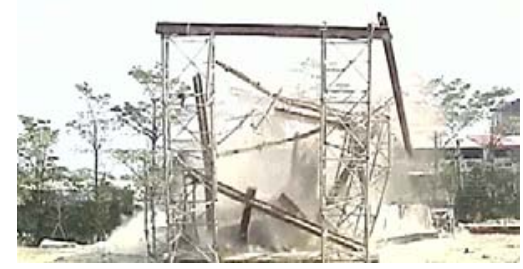

(7)

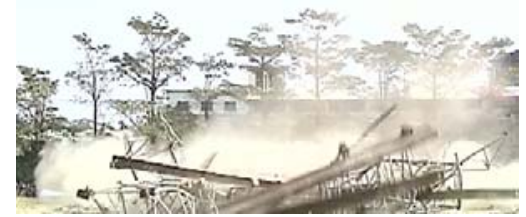

(8)

Figure 16B. Collapse of Outdoor Heavy-duty Scaffolds with Shores under Loading, as recorded by Camera on the West 


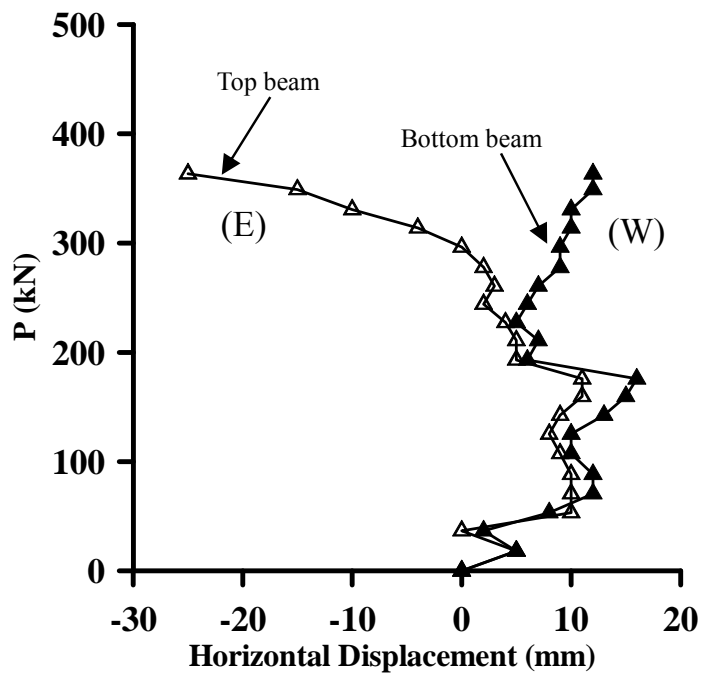

Figure 17. Load-displacement Relation of Upper- and Lower- Story H-beams, obtained by Theodolite on the North

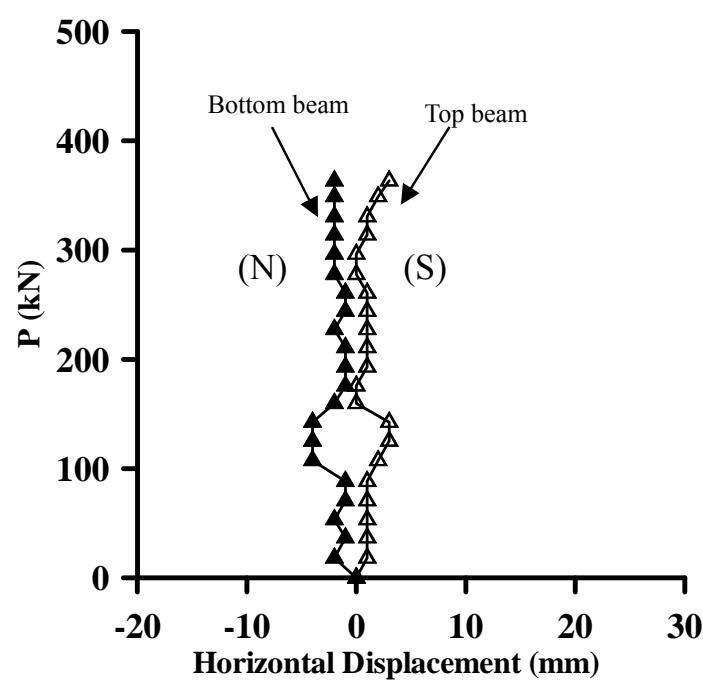

Figure 18. Load-displacement Relation of Upper- and Lower-story H-beams, obtained by Theodolite on the West 


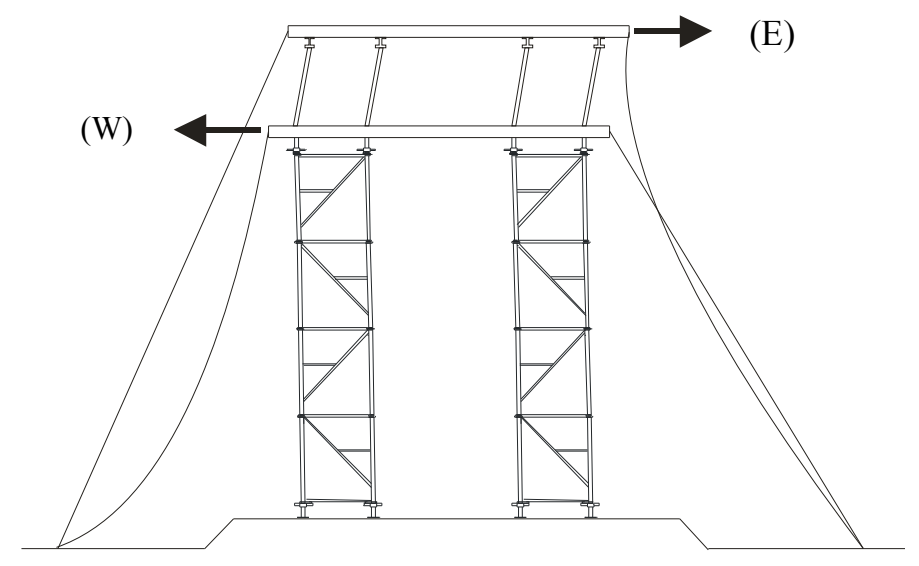

Figure 19. Buckling Failure of Outdoor Heavy-duty Scaffold System with Shores under Loading

Table 2. Weights of RC Blocks and Sandbags and Displacements Recorded on Theodolites during Outdoor Load Test on Full-scale Heavy-duty Scaffolds with Shores

\begin{tabular}{|c|c|c|c|c|c|c|c|c|c|}
\hline \multirow{2}{*}{ Record No. } & \multirow{2}{*}{$\begin{array}{c}\text { Cumulative load } \\
(\mathrm{kN})\end{array}$} & \multicolumn{4}{|c|}{ Theodolite on the north $(\mathrm{mm})$} & \multicolumn{4}{|c|}{ Theodolite on the west $(\mathrm{mm})$} \\
\hline & & $\mathrm{D}_{\mathrm{NT}}$ & $\Delta_{\mathrm{NT}}$ & $\mathrm{D}_{\mathrm{NB}}$ & $\Delta_{\mathrm{NB}}$ & Dwt & $\Delta \mathrm{WT}$ & Dwв & $\Delta \mathrm{WB}$ \\
\hline 0 & 0.000 & 430 & 0 & 340 & 0 & 380 & 0 & 365 & 0 \\
\hline 1 & 18.270 & 435 & 5 & 345 & 5 & 381 & 1 & 363 & -2 \\
\hline 2 & 36.677 & 430 & 0 & 342 & 2 & 381 & 1 & 364 & -1 \\
\hline 3 & 53.319 & 440 & 10 & 348 & 8 & 381 & 1 & 363 & -2 \\
\hline 4 & 70.657 & 440 & 10 & 352 & 12 & 381 & 1 & 364 & -1 \\
\hline 5 & 88.378 & 440 & 10 & 352 & 12 & 381 & 1 & 364 & -1 \\
\hline 6 & 107.422 & 439 & 9 & 350 & 10 & 382 & 2 & 361 & -4 \\
\hline 7 & 125.319 & 438 & 8 & 350 & 10 & 383 & 3 & 361 & -4 \\
\hline 8 & 142.540 & 439 & 9 & 353 & 13 & 383 & 3 & 361 & -4 \\
\hline 9 & 159.741 & 441 & 11 & 355 & 15 & 380 & 0 & 363 & -2 \\
\hline 10 & 175.745 & 441 & 11 & 356 & 16 & 380 & 0 & 364 & -1 \\
\hline 11 & 193.113 & 435 & 5 & 346 & 6 & 381 & 1 & 364 & -1 \\
\hline 12 & 210.902 & 435 & 5 & 347 & 7 & 381 & 1 & 364 & -1 \\
\hline 13 & 227.387 & 434 & 4 & 345 & 5 & 381 & 1 & 363 & -2 \\
\hline 14 & 244.097 & 432 & 2 & 346 & 6 & 381 & 1 & 364 & -1 \\
\hline 15 & 260.778 & 433 & 3 & 347 & 7 & 381 & 1 & 364 & -1 \\
\hline 16 & 277.803 & 432 & 2 & 349 & 9 & 380 & 0 & 363 & -2 \\
\hline 17 & 296.377 & 430 & 0 & 349 & 9 & 380 & 0 & 363 & -2 \\
\hline 18 & 313.950 & 426 & -4 & 350 & 10 & 381 & 1 & 363 & -2 \\
\hline 19 & 330.680 & 420 & -10 & 350 & 10 & 381 & 1 & 363 & -2 \\
\hline 20 & 349.078 & 415 & -15 & 352 & 12 & 382 & 2 & 363 & -2 \\
\hline 21 & 363.405 & 405 & -25 & 352 & 12 & 383 & 3 & 363 & -2 \\
\hline \multicolumn{10}{|c|}{$\begin{array}{l}\text { Notes: } \\
\text { 1. } \Delta \mathrm{ET} 、 \Delta \mathrm{EB} 、 \Delta \mathrm{NT} 、 \Delta \mathrm{NB}: \text { Record number }(1 \sim 21)-\text { Record number }(0) \\
\text { 2. D:original value; } \Delta \text { :calibration value; w:west; N:north; т:top H-beam; } \text { : }: \text { bottom H-beam }\end{array}$} \\
\hline
\end{tabular}

\subsubsection{Load Capacity in Outdoor Test, Estimated from Indoor Test}

As shown in Table 1, the load capacity of the indoor two-story heavy-duty scaffolds with $150 \mathrm{~cm}$-long thin steel shores was $216.45 \mathrm{kN}$. When this scaffold system failed, the upper-story thin steel shores deformed apparently but the lower story heavy-duty scaffolds deformed much less. Multiplying the load capacity of this independent two-story heavy-duty scaffolds that were test indoors by four yielded a possible load of $865.8 \mathrm{kN}(=216.45 \times 4)$. 
Four sets of four-story heavy-duty scaffolds that were augmented on top with $150 \mathrm{~cm}$-long thin steel shores were used in the outdoor test. However, the horizontal restraint of the steel wire ropes that was used in the outdoor test was not as good as that of the steel holder on the top of the universal testing machine that was used in the indoor tests.

Comparing the fourfold load capacity of the indoor two-story heavy-duty scaffolds augmented on top with $150 \mathrm{~cm}$-long thin steel shores with the load capacities of the outdoor four-story heavy-duty scaffold system augmented on top with $150 \mathrm{~cm}$-long thin steel shores $(363.418 \mathrm{kN})$ revealed that the load capacity in the outdoor test was $42 \%(=(363.418 / 865.8) \times 100 \%)$ of that in the indoor test. Thus, engineers should not calculate the load capacity of an outdoor heavy-duty scaffold system with shores based on an indoor test of an independent heavy-duty scaffold system with shores.

\subsection{Test results and second-order inelastic analyses of heavy-duty scaffold systems}

\subsubsection{Indoor heavy-duty scaffolds with shores}

\subsubsection{Restraint Boundary}

In this study, a second-order inelastic analysis with semi-rigid joints of the indoor independent two-story heavy-duty scaffolds with $150 \mathrm{~cm}$-long thin steel shores on top was conducted. Figure 4 displays the dimensions of the combined system that was used in the analysis. The cross-sections of various members of the heavy-duty scaffolds and thin steel shores are as described in previous sections. An $E_{r}$ (reduced modulus) of $14,715 \mathrm{kN} / \mathrm{cm}^{2}\left(1500\right.$ tonne $\left./ \mathrm{cm}^{2}\right)$ was utilized in this study.

Based on the method that was used by Peng et al. [10], the stiffnesses of the joints in the scaffold systems were estimated by comparing the results of a second-order inelastic analysis with semi-rigid joints with the relevant test results. In this study, the stiffness of the joints in various members of the heavy-duty scaffolds were estimated as follows; the stiffness of the join between the vertical main rods was $5,688 \mathrm{kN}-\mathrm{cm} / \mathrm{rad}$; the stiffness of the top jack and the jack base was $9,807 \mathrm{kN}-\mathrm{cm} / \mathrm{rad}$, and the stiffness of the joints between horizontal bars and between diagonal braces was the stiffness of typical hinge joints. Based on these joint stiffnesses and the second-order inelastic analysis with semi-rigid joints, the critical load of the independent two-story heavy-duty scaffolds with shores was estimated to be $207.908 \mathrm{kN}$, which was around $96 \%$ of the value obtained in the test $(=(207.908 / 216.45) \times 100 \%)$.

Figure 20 displays the deformation of the independent two-story heavy-duty scaffolds with shores under loading based on a second-order inelastic analysis with semi-rigid joints, which is very close to that obtained in the test. Figure 11(B) exhibits the deformation obtained in the test. As displayed in Figure 20, the top of the $150 \mathrm{~cm}$-long thin steel shores are restrained in the $\mathrm{x}$-direction and the z-direction but not in the y-direction. Figure 21 plots the P- $\Delta$ curve of the relationship between the lateral displacement and the total vertical load at point $\mathrm{A}$ in Figure 20 in the $\mathrm{z}$ direction.

\subsubsection{Unrestrained boundary simulated by linear spring}

In the outdoor load test on the heavy-duty scaffold system with shores, eight steel wire ropes were set up on the top of the scaffold system to provide a restrained boundary. However, in the load tests, these eight steel wire ropes relaxed and lateral displacements occurred on the top of the scaffold system. In the second-order inelastic analysis, the linear spring simulated this unrestraint boundary with lateral displacements. 
In the second-order inelastic analysis of the independent two-story heavy-duty scaffolds with $150 \mathrm{~cm}$-long thin steel shores under spring-like boundary conditions, the boundaries of the top story of the scaffold system were allowed to move in $\mathrm{x}, \mathrm{y}$ and $\mathrm{z}$ directions. However, at the top of the four thin steel shores, the stiffness of $0.4 \mathrm{kN} / \mathrm{cm}$ of the linear spring simulated the boundary conditions in the $\mathrm{x}$ and $\mathrm{z}$ directions. Figure 22 presents the arrangements of the linear springs. The second-order inelastic analysis yields the critical load of this scaffold system as $191.237 \mathrm{kN}$, which is lower than that of the previous system with the restrained boundary $(207.908 \mathrm{kN})$. Figure 23 displays the deformation of the second-order inelastic analysis of the heavy-duty scaffold system with shores under loading. Figure 24 plots the P- $\Delta$ curve of the vertical load and lateral displacement of point $\mathrm{A}$ in Figure 23 in the $\mathrm{z}$ direction.

\subsubsection{Outdoor Heavy-duty Scaffold System with Shores}

In the tests on the outdoor heavy-duty scaffold system with shores, steel wire ropes were used to constrain the top story but relaxation occurred during the test. Therefore, in the second-order inelastic analysis of this scaffold system, the linear springs were used to simulate the unrestrained boundary conditions of the top story of the scaffold system. The linear spring with a stiffness of 0.4 $\mathrm{kN} / \mathrm{cm}$ simulated the boundary condition in the $\mathrm{x}$ and $\mathrm{z}$ directions at the four corners of the scaffold system. Figure 25 displays the arrangement of the linear springs in the scaffold system.

Based on the joint stiffness that was obtained in the second-order inelastic analysis of the aforementioned indoor two-story heavy-duty scaffold system with shores, a second-order inelastic analysis of the outdoor heavy-duty scaffold system with shores just yielded a critical load of $356.612 \mathrm{kN}$. This analytical value is very close to the test value $(363.418 \mathrm{kN})$. Figure 26 shows the deformation obtained in the second-order inelastic analysis of the heavy-duty scaffold system with shores under loading. Figure 27 plots the P- $\Delta$ curve of load and lateral displacement of point $\mathrm{A}$ in Figure 26 in the $\mathrm{x}$ direction.

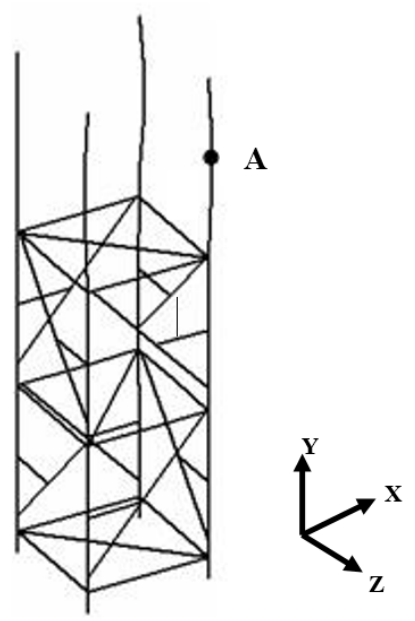

Figure 20. Deformation obtained by Second-order Inelastic Analysis of Independent Heavy-duty Scaffolds with 150cm-long Thin Steel Shores on Top 


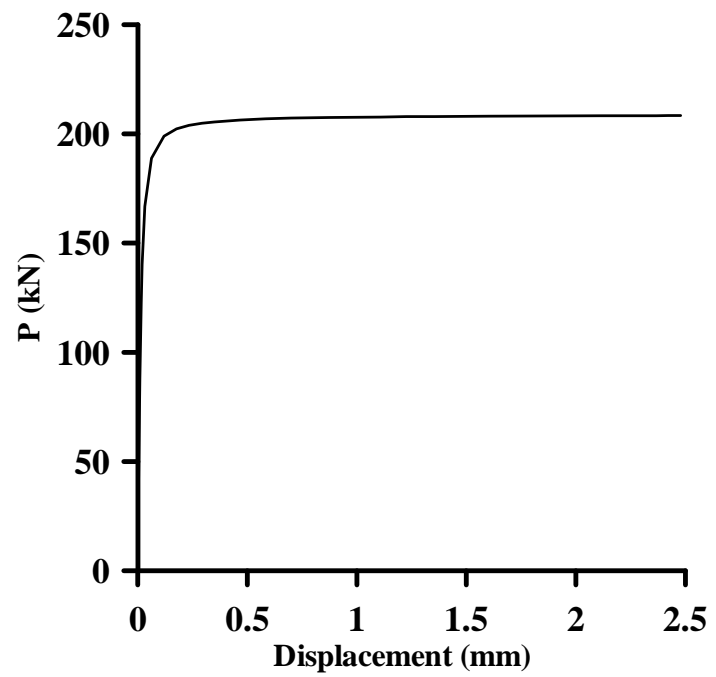

Figure 21. P- $\Delta$ Curve obtained by Second-order Inelastic Analysis of Independent Heavy-duty Scaffolds with $150 \mathrm{~cm}$-long Thin Steel Shores on Top (in z direction)

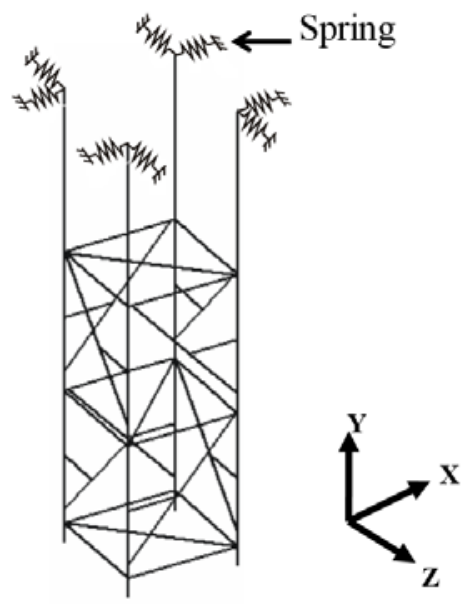

Figure 22. Configuration of Spring Boundary Condition in Second-order Inelastic Analysis of Independent Heavy-duty Scaffolds with $150 \mathrm{~cm}$-long Thin Steel Shores on Top 


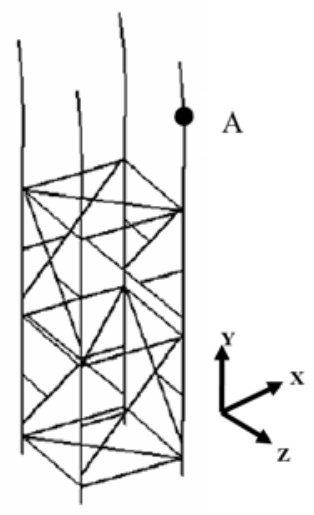

Figure 23. Deformation obtained by Second-order Inelastic Analysis of Independent Heavy-duty Scaffolds with $150 \mathrm{~cm}-$ long Thin Steel Shores using Linear Spring Boundary Condition

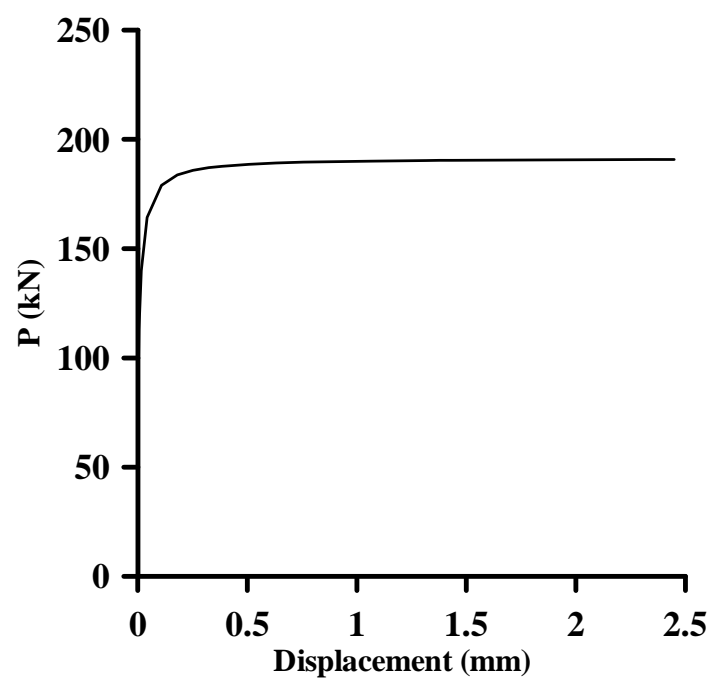

Figure 24. P- $\Delta$ Curve obtained by Second-order Inelastic Analysis of Independent Heavy-duty Scaffolds with $150 \mathrm{~cm}-$ long Thin Steel Shores using Linear Spring Boundary Condition (in $\mathrm{z}$ direction) 


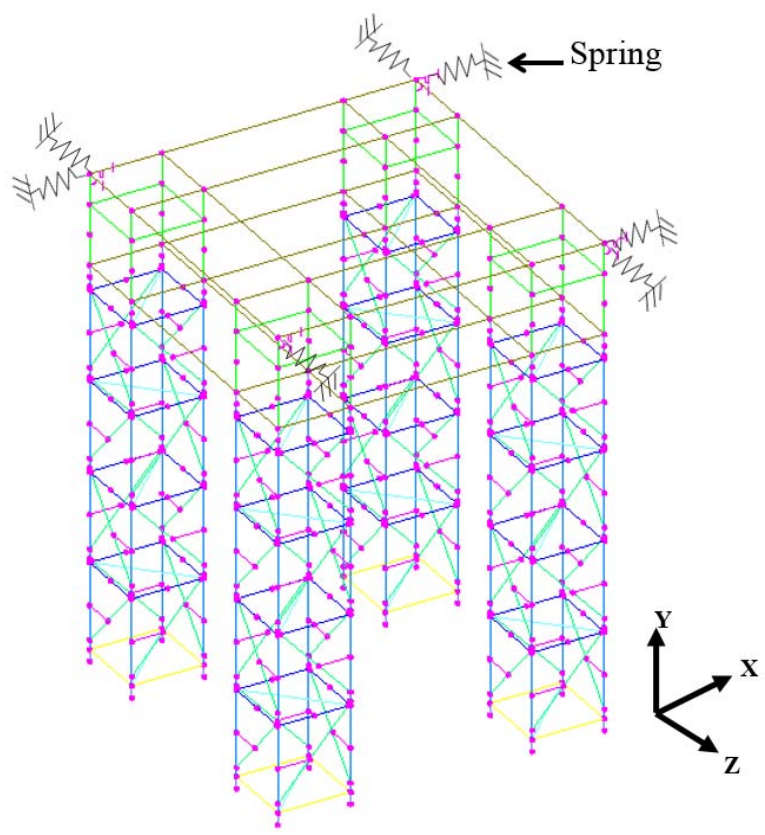

Figure 25. Configuration of Spring Boundary Condition in Second-order Inelastic Analysis of Heavy-duty Scaffold System with 150cm-long Thin Steel Shores on Top

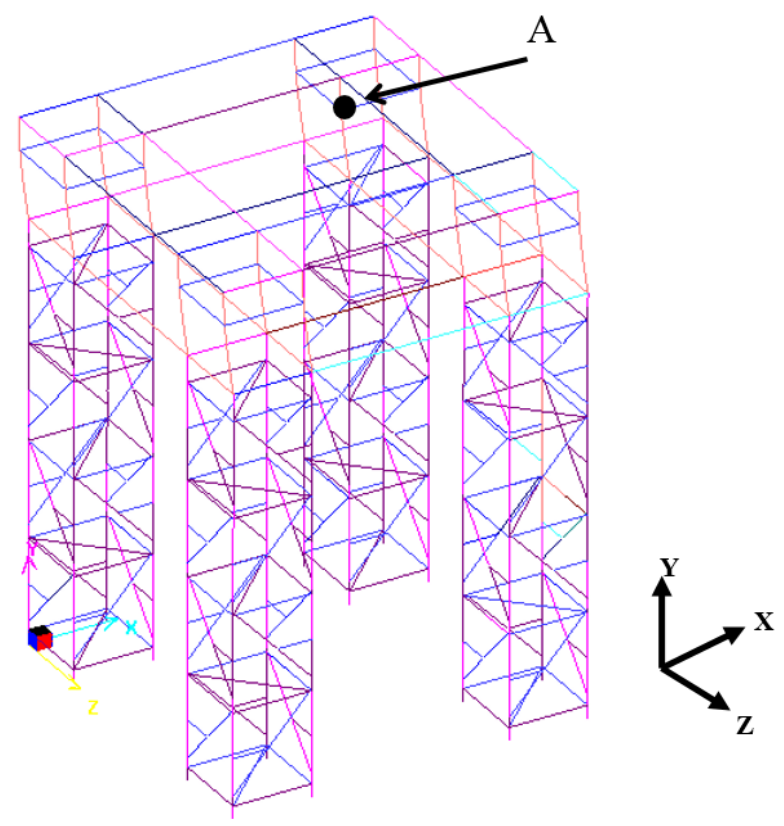

Figure 26. Deformation obtained by Second-order Inelastic Analysis of Heavy-duty Scaffold System with Shores using Linear Spring Boundary Condition 


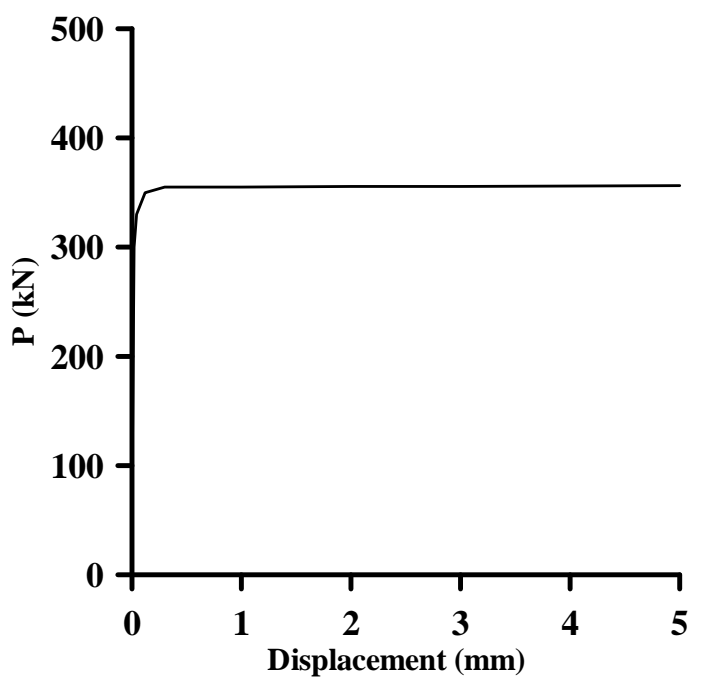

Figure 27. P- $\Delta$ curve obtained by Second-order Inelastic Analysis of Heavy-duty Scaffold System with Shores using Linear Spring Boundary Conditions (in x direction)

\section{CONCLUSIONS}

This study involved both practical tests and analyses, and the following findings were obtained.

1. The load capacities of two-story and three-story heavy-duty scaffolds are close to each other and their failure models are similar. Therefore, the load capacity of heavy-duty scaffolds may not significantly decline as the number of stories increases.

2. The load capacity of two-story heavy-duty scaffolds that are augmented on top with $1.5 \mathrm{~m}$-long thin steel shores is much lower than that of three-story heavy-duty scaffolds with the same height. Engineers should avoid adopting the heavy-duty scaffolds with thin steel shores on construction sites.

3. The load capacity of two-story heavy-duty scaffolds that are augmented on top with $1.5 \mathrm{~m}$-long thick steel shores is very close to that of three-story heavy-duty scaffolds with the same height. This test result herein may serve as a reference for construction contractors in installing safe heavy-duty scaffolds with shores when necessary.

4. Owing to the uneven settlement of the overall heavy-duty scaffold system with shores in the outdoor test, relaxation occurred on the steel wire ropes, causing lateral displacement of the top of the combined scaffold system. Therefore, the critical load of the heavy-duty scaffold system with shores was lower than the expected value. Engineers need to check the uneven settlement of the base of heavy-duty scaffold system with shores on construction sites before the installation.

5. In the second-order inelastic analysis with semi-rigid joints for the outdoor heavy-duty scaffold system with shores, linear springs at the top of the system were used to simulate the lateral displacement of the boundaries due to the relaxation of the steel wire ropes. The analytical values that were generated using this method were very close to the values obtained in the test.

6. In a rough design, the load capacity of a heavy-duty scaffold system with shores is estimated based on that of indoor independent heavy-duty scaffolds without shores. This approximate method tends to misestimate the load capacity of the overall heavy-duty scaffold system with shores, leading to an extremely high risk of collapse, as demonstrated by the outdoor tests in this study. 


\section{ACKNOWLEDGEMENTS}

The authors would like to thank the Ministry of Science and Technology for funding this study (MOST 105-2221-E-224-015), Taiwan Hao-Ji Company for providing test materials, and Mr. Ming-zhi Jian for helping to perform the tests. Without their supports, this study would not have been completed.

\section{REFERENCES}

[1] Chan, S.L., "Geometric and Material Nonlinear Analysis of Beam-columns and Frames using the Minimum Residual Displacement Method", International Journal for Numerical Method in Engineering, 1988, Vol. 26, pp. 2657-2669.

[2] Chan, S.L. and Cho, S.H., "Second-order P- $\Delta-\delta$ Analysis and Design of Angle Trusses Allowing for Imperfections and Semi-rigid Connections", International Journal of Advanced Steel Construction, 2005, Vol. 1, No. 1, pp. 157-172.

[3] Chan S.L. and Zhou Z.H., "A Pointwise Equilibrium Polynomial (PEP) Element for Nonlinear Analysis of Frame", Journal of Structural Engineering ASCE, 1994, Vol. 120, No. 6, pp. 1703-1717.

[4] Huang, Y.L., Kao, Y.G. and Rosowsky, D.V., "Load-carrying Capacities and Failure Modes of Scaffolding Shoring Systems, Part II: Analytical model and its closed-form Solution," Structural Engineering and Mechanics, 2000, Vol. 10, No. 1, pp.53-66.

[5] Liu, H., Zhao, Q., Wang, X., Zhou, T., Wang, D., Liu, J. and Chen, Z., "Experimental and Analytical Studies on the Stability of Structural Steel Tube and Couple Scaffolds without X-bracing," Engineering Structures, 2010, Vol. 32, pp.1003-1015.

[6] Kuo, C.C., Peng, J.L., Yen, T. and Chan, S.L., "Experimental Study of Modular Falsework System with Wooden Shores under Various Path Loads," Advances in Structural Engineering, 2008, Vol. 11, No.4, pp.369-382.

[7] Peng, J.L., Ho, C.M., Chen, C.Y. and Yang, Y.B., "Experimental Study on Load Capacities of Isolated Heavy-Duty Scaffolds Used in Construction," Journal of Advanced Steel Construction, 2014, Vol. 10, No. 3, pp.248 273.

[8] Peng, J.L., Ho, C.M., Lin, C.C. and Chen, W.F., "Load-Carrying Capacity of Single-Row Steel Scaffolds with Various Setups", Journal of Advanced Steel Construction, 2015, Vol. 11, No.2, pp.185 210.

[9] Peng, J.L., Yen, T., Lin, I., Wu, K.L. and Chen, W.F., "Performance of Scaffold Frame Shoring under Pattern Loads and Load Paths," Journal of Structural Engineering, 1997, ASCE, Vol. 123, No. 2, pp138-145.

[10] Peng, J.L., Yen, T., Kuo, C.C. and Chan, S.L., "Analytical and Experimental Bearing Capacities of System Scaffolds," Journal of Zhejiang University Science A, 2009, Vol.10, No.1, pp.82-92.

[11] Peng, J.L., Wu, C.L. and Chan, S.L., "Sequential Pattern Load Modeling and Warning-system Plan in Modular Falsework," Structural Engineering and Mechanics, 2003, Vol. 16, No. 4, pp.441-468.

[12] Zhang, H., Chandrangsu, T. and Rasmussen, K.J.R., "Probabilistic Study of the Strength of Steel Scaffold Systems," Structural Safety, 2010, Vol.32, pp.393-401.

[13] Zhang, H., Rasmussen, K.J.R. and Ellingwood, B.R., "Reliability Assessment of Steel Scaffold Shoring Structures for Concrete Formwork", Engineering Structures, 2012, Vol. 36, pp.81-89. 